\title{
Patch occupancy by squirrels in fragmented deciduous forest: effects of behavior
}

\author{
Aaron A. Walpole • Jeff Bowman
}

Received: 19 February 2010 / Accepted: 7 September 2010 /Published online: 5 November 2010

(C) Mammal Research Institute, Polish Academy of Sciences, Bialowieza, Poland 2010

\begin{abstract}
We tested whether species-specific behavioral traits could explain patterns of habitat patch occupancy by five different squirrel species in Ontario, Canada: the northern and southern flying squirrel (Glaucomys sabrinus and Glaucomys volans), the North American red squirrel (Tamiasciurus hudsonicus), the eastern chipmunk (Tamias striatus), and the eastern gray squirrel (Sciurus carolinensis). Flying squirrel species exhibit group nesting in winter, which may put them at risk of extirpation in small patches with few individuals to contribute to group nests. Flying squirrels are also volant, potentially making non-treed matrix a barrier. Our surveys revealed that G. sabrinus was most likely to occur in large patches that were embedded in landscapes with low connectivity, and least likely to occur in small patches in highly connected landscapes. Conversely, G. volans was most likely to occur in large, well-connected patches and least likely to occur in small, unconnected patches. Patch occupancy by the cursorial squirrels was not strongly influenced by patch area or isolation. These findings reinforce previous studies suggesting that an understanding of species-specific traits such as behavior is an important consideration when interpreting habitat fragmentation effects.
\end{abstract}

Communicated by: Magdalena Niedziałkowska

A. A. Walpole

Department of Biology, Trent University,

1600 West Bank Drive,

Peterborough, ON K9J 7B8, Canada

e-mail: aaronwalpole@trentu.ca

J. Bowman $(\bowtie)$

Wildlife Research and Development Section,

Ontario Ministry of Natural Resources,

DNA Building, 2140 East Bank Drive,

Peterborough, ON K9J 7B8, Canada

e-mail: jeff.bowman@ontario.ca
Keywords Allee effect - Connectivity - Glaucomys . Occupancy $\cdot$ Sciuridae $\cdot$ Habitat area

\section{Introduction}

Habitat fragmentation threatens biodiversity on a global scale. The process of habitat fragmentation includes an overall reduction in the amount of habitat and size of habitat patches (habitat loss), as well as an increase in the amount of patches and the level of isolation between them (fragmentation per se; Fahrig 2003; Fischer and Lindenmayer 2007). The effects of these processes are species specific but generally result in fewer, smaller, and more isolated populations compared to contiguous habitats. Through a combination of environmental, genetic, and demographic stochasticity, smaller populations in smaller habitat patches suffer an increased risk of local extinction compared to larger populations (Shaffer 1981). This has been termed an area effect (e.g., Ferraz et al. 2007).

Problems related to area effects are compounded as patches become increasingly isolated, since isolation limits inter-patch movement. A common assumption in metapopulation research is that populations exist in a state of dynamic equilibrium between local extinctions and colonizations (Moilanen and Hanski 1998) such that the persistence of populations relies on immigrating conspecifics to reduce extinction risk, a process referred to as the "rescue effect" (e.g., Brown and Kodric-Brown 1977). As populations become isolated beyond the potential of rescue, the risk of permanent local extinction of the patch increases, and thus the risk of metapopulation extinction also increases (Moilanen and Hanski 1998). Together, negative impacts associated with area and isolation effects can increase the risk of extinction for many species (Caughley 
and Gunn 1996; Fahrig 2002; Ostfeld and LoGiudice 2003; Ferraz et al. 2007) and hence, human activities that contribute to the process of habitat fragmentation are considered a threat to biodiversity (Fischer and Lindenmayer 2007)

Several studies have shown effects of habitat area and isolation on small-mammal demography. For example, habitat patch area is negatively related to population density and positively related to home range size of cursorial squirrels (Koprowski 2005; Reunanen and Grubb 2005) and can affect the age structure and sex ratio of small generalist rodents (Wilder and Meikle 2006). Further, reducing habitat isolation increased gene flow among populations of the European red squirrel (Sciurus vulgaris) in Britain (Hale et al. 2001).

Hypotheses concerning area and isolation effects on patch occupancy have often been related to body size. In general, larger-bodied species have been considered more at risk of extinction in small patches, but also more able to colonize isolated patches (Laurance 1991; Bright 1993; Nupp and Swihart 2000). For example, Nupp and Swihart (2000) predicted that sensitivity of a small-mammal assemblage to habitat patch area should vary with body size due to allometrically scaled population densities. They found no covariation in their Indiana study area, however, between body size and patch occupancy. Body size has also been suggested to increase patch colonization ability by increasing perceptual range. For example, larger-bodied mammals can see farther, and therefore, should have greater success at colonizing distant habitat patches (Mech and Zollner 2002).

Given the uncertainty around the effects of body size on patterns of patch occupancy (Laurance 1991; Nupp and Swihart 2000), we wished to test an alternative hypothesis. There is a growing recognition by landscape ecologists that species-specific traits are important to understand when making predictions about fragmentation effects (e.g., Fahrig 2001; Bowman et al. 2002a; Jaeger et al. 2005). Combining this with the understanding that animal behavior plays an important role in species responses to fragmentation (Lima and Zollner 1996), we sought to test whether speciesspecific behavioral traits would explain patterns of patch occupancy better than body size in small-mammal assemblages. Two traits of particular interest to us were mode of travel and over-wintering strategy. We tested these hypotheses on an assemblage of sciurid rodents in an agricultural and exurban region of southern Ontario. Squirrels are forestdependent mammals that often respond negatively to fragmented landscapes that are dominated by agriculture (Taulman and Smith 2004; Koprowski 2005). We examined patterns of patch occupancy of five local squirrel species: the eastern chipmunk (Tamias striatus), the eastern gray squirrel (Sciurus carolinensis), the North American red squirrel (Tamiasciurus hudsonicus), the northern flying squirrel
(Glaucomys sabrinus), and the southern flying squirrel (Glaucomys volans). Thus, we examined the effects of fragmentation on a suite of squirrel species and had a particular focus on the role of behavioral traits in affecting responses to patch area and isolation.

Flying squirrels are social animals that form aggregations in winter (Cotton and Parker 2000; Nupp and Swihart 2000), allowing them to conserve energy while maintaining thermal equilibrium (Stapp et al. 1991; Merritt et al. 2001; Bowman et al. 2005; Garroway et al. 2010). Group nesting is a form of positive density dependence, or Allee effect, which results in increased survival and ultimately fitness (Courchamp et al. 1999). The benefits to thermal equilibrium diminish as aggregation size decreases, until at some threshold aggregation size, population extirpation becomes more likely (Courchamp et al. 1999). Although winter aggregations have been observed in other squirrel species, such as gray squirrels (Koprowksi 1996), flying squirrels appear particularly dependent on this strategy. As a consequence, it seems likely that flying squirrels must occupy habitat patches large enough to sustain a sufficient number of individuals to ensure their survival through winter (Nupp and Swihart 2000). Conversely, we predicted that the other squirrel species in our study would be more capable of persisting in small patches in the absence of conspecifics because they do not rely as heavily on aggregations in winter. Thus, we hypothesized that among sciurids, flying squirrels are particularly sensitive to area effects.

We also hypothesized that the locomotive strategies of each species would influence their dispersal capabilities in a fragmented landscape, and therefore, their ability to rescue extirpated habitats. Some previous studies have suggested that flying squirrels are incapable of traveling great distances across non-forested matrix (Rosenblatt et al. 1999; Selonen and Hanski 2003; Ritchie et al. 2009; but see Rizkalla and Swihart 2007) making them sensitive to isolation effects. Therefore, we predicted that in addition to habitat area effects, flying squirrel patch occupancy would be positively related to structural connectivity of the forest surrounding the focal habitat patch. Conversely, cursorial squirrels should show a greater tolerance for landscapes with low structural forest connectivity since they do not rely on gliding between trees for movement (e.g., Bowman and Fahrig 2002; Patterson and Malcolm 2010).

\section{Study area}

This research was conducted near Peterborough, ON, Canada $\left(44^{\circ} 17^{\prime} \mathrm{N}, 78^{\circ} 19^{\prime} \mathrm{W}\right)$. We sampled squirrels in 30 deciduous forest patches ranging in size from 1.1 to $>1,000$ ha in landscapes ranging from highly fragmented to contiguous forest. The mean [SE] distance between geographic centroids 
of focal forest patches in these landscapes was $31[1.5] \mathrm{km}$, respectively. Forest patches were surrounded by pasture, corn, soybean, wheat, hay, or untended meadows, as well as lowdensity housing. Each site was dominated by mature deciduous trees including mainly sugar maple (Acer saccharum), white ash (Fraxinus americana), basswood (Tilia americana), black cherry (Prunus serotina), ironwood (Ostrya virginiana), and white birch (Betula papyrifera). All sites contained at least one masting species such as American beech (Fagus grandifolia), and red or white oak (Quercus rubra or Quercus alba). All sites were similar in tree species composition and were classified as Ecosite 26 [Sugar Maple-Basswood] using the Field Guide to Forest Ecosystems of Central Ontario (Chambers et al. 1997), except for our most northern site (Kawartha Highlands) which was classified as Ecosite 27 [Sugar Maple-White Birch-Poplar-White Pine (Pinus strobus)] in approximately half of the site and Ecosite 26 in the other half of the site.

\section{Material and methods}

\section{Squirrel sampling}

Most fieldwork was conducted from August to October 2006, when 24 deciduous forest patches were sampled. Six additional patches were sampled during the summers of 2004 $(n=4)$ and $2005(n=2)$, for a total sample size of 30. Forest patches were selected in order to capture a range in focal patch area and isolation. In 2006 each site was subject to three 24-h trap sessions using model 102 Tomahawk live traps (Tomahawk Live Trap Co., Tomahawk, WI) placed horizontally in live trees $(>20 \mathrm{~cm}$ in diameter) about $2 \mathrm{~m}$ above ground. A patch was sampled with a $5 \times 6$ grid and 20-m spacing between each trap station for a total of 30 traps per patch. All captured individuals were identified and marked with numbered 1-g Monel ear tags (National Band and Tag Co., Newport, KY). Traps were checked twice daily, in the morning and evening, since both nocturnal and diurnal species were potentially present at the sites. Traps were baited with sunflower hearts. All animal use procedures were approved by the Trent University and OMNR Animal Care Committees.

In 2006, each patch was trapped with an effort of 90 total trap nights (tn). In 2004 and 2005, patches were sampled using a similar trap set although trap nights varied slightly. In 2005, the two patches had 80 and 99 tn. In 2004, the four patches were sampled with 55, 285, 71, and $60 \mathrm{tn}$. The occurrence of each of the five sciurid species was assessed at each patch.

Area and isolation metrics

For each sampled forest patch, area and habitat connectivity measures were obtained from digitized aerial photographs
(Ontario Ministry of Natural Resources, unpublished data) identifying forest (patches and hedgerows) and non-forest areas. We defined a forest patch as any wooded area that was more than $50 \mathrm{~m}$ from another wooded area. Any patch $<50 \mathrm{~m}$ from the focal patch was considered part of the focal patch area. Patches were selected such that they were not connected to other habitats with hedgerows. The $50-\mathrm{m}$ separation between patches was chosen for our study because it exceeded the mean gliding distance of flying squirrels ( $16.4 \mathrm{~m}$ for $G$. sabrinus; Vernes 2001), and it was a suitable distance allowing us to identify isolated patches according to the resolution of the digitized aerial photographs. It became difficult to segregate patches from the larger forest complex of hedgerows and close neighboring patches when they exceeded 1,000 ha. Thus, we followed the procedure of Nupp and Swihart (2000) and assigned a size of 1,000 ha to such patches. We $\log _{10}$-transformed patch area to improve normality of the patch area variable for our analysis.

There are many potential measures of landscape structural connectivity. A buffer method is effective when the buffer radius is chosen to match the average dispersal distance of the focal species (Moilanen and Nieminen 2002; Bender et al. 2003; Prugh et al. 2008). We used the buffer method with a radius of $5,000 \mathrm{~m}$ from the patch centroid to quantify the structural connectivity of the forested landscape surrounding the focal patch. This buffer radius was chosen based on exploratory analyses where we optimized the balance between a low correlation with patch area and a sufficient resolution for estimates to be relevant to dispersing squirrels (Bowman et al. 2002b). We measured connectivity as the proportion of forest habitat within $5,000 \mathrm{~m}$ of the patch centroid (Moilanen and Nieminen 2002). We sought an additional measure that would also reflect landscape configuration. In particular, we were interested in a measure that would indicate the prevalence of forest-matrix edges, as such edges might be perceived by volant species as barriers. Thus, we estimated the total edge density within each 5,000-m buffer using Patch Analyst 2.2 (Elkie et al. 1999) in ArcView GIS 3.2 (ESRI, Redlands, CA, USA).

We controlled for the effect of focal patch area on our connectivity measure by using the residual values from a linear regression of $\log _{10}$-transformed area and the buffer measure. Residuals of this regression reflected the amount of forest surrounding the focal patch independent of the size of the focal patch. We used these residual values as our variable, which we called "connectivity," We recognize that using residuals in this way has potential to increase the relative importance of patch area compared to connectivity (Koper et al. 2007). Given that we were principally interested in a comparison among species, we did not view this as a concern. Our measure of connectivity was negatively correlated with edge density $(r=-0.66, n=30$, 
$P<0.001)$. We controlled for this correlation by regressing edge density against the original, unaltered measure of connectivity (i.e., the proportion of forest cover within $5,000 \mathrm{~m}$ of patch centroid), and used the residuals of this regression as our measure of edge density. The three variables: patch area, connectivity, and edge comprised the basis for all models we used to predict sciurid patch occupancy.

\section{Data analysis}

We calculated species latency-to-detection by averaging the minimum number of trap nights needed to detect each species from all occupied sites. Further, we calculated detection probability for each species from repeat visits at each site (MacKenzie et al. 2002, 2003), treating one night of trapping in each focal patch as a visit.

We tested whether patterns of patch occupancy appeared related to body size. In particular, we tested whether smaller patches were more likely to be absent of larger-bodied squirrels, and we tested whether connected patches were more likely be occupied by smaller-bodied squirrels. For each patch, we rank-transformed the patch area and connectivity variables. We also ranked the squirrel species in any patch according to body size using average adult male weights for each species from our study. We then computed Spearman rank correlations to test whether mean body-size rank of squirrels occupying patches was related to habitat area or habitat amount.

To test our hypotheses related to mode of travel and over-wintering strategies, we created occupancy models in Program Presence (Hines 2006) to examine the effects of the three habitat variables (and their additive combinations) on probability of occurrence of each squirrel species. Global models for all species had c-hat values $>1$ suggesting that data was overdispersed. Thus, we used quasi-likelihood adjusted Akaike's Information Criterion corrected for small sample sizes (QAICc) and quasi- likelihood adjusted Akaike's Weights $\left(w_{i}\right)$ to correct for over dispersion and evaluate parsimony of candidate models (Anderson 2008). Candidate models were those with QAICc values $<2$ units from the top model or ranked above the null model; these were model averaged to create composite models (Burnham and Anderson 2002) of squirrel patch occupancy for each species.

We evaluated the performance of occupancy models with area under the curve (AUC) from receiver operator characteristic curves (Hosmer and Lemeshow 2000; Manel et al. 2001). Area under the curve is a measure of the models ability to correctly discriminate binary outcomes based on the true positives (sensitivity) and false positives (1-specificity) predicted by the model. Predicted values were estimated from occupancy probabilities multiplied by the probability of not detecting a species per site (as in Moore and Swihart 2005). An AUC value of 0.5 corresponding to a straight $45^{\circ}$ angle line on the curve suggests that the model is no better than random. An AUC of 0.5 to 0.7 indicates a model has low predictive power, whereas 0.7 to 0.9 is moderate to good and greater than 0.9 is excellent (Manel et al. 2001; Boyce et al. 2002).

\section{Results}

Across the 30 landscapes, we conducted 2,810 tn and captured 93 eastern chipmunks, 48 gray squirrels, 20 red squirrels, 37 northern flying squirrels, and 16 southern flying squirrels. Based on frequency of occurrence, eastern chipmunks and gray squirrels were the most common species captured (each occurring in 16 of the 30 sites), followed by northern flying squirrels (11 sites), red squirrels ( 9 sites), and southern flying squirrels ( 5 sites). There was a significant increase in species richness with increasing forest patch area $\left(r^{2}=0.30, n=30, P=\right.$ 0.0017). Southern flying squirrels occurred in the largest, most well-connected patches in landscapes with the lowest edge densities (Table 1). On the other hand, eastern

Table 1 Mean (standard error) values of descriptive metrics for forest patches occupied by five squirrel species in a study area in central Ontario, Canada

\begin{tabular}{lllll}
\hline & $N$ & Patch area (ha) & Connectivity (\%) & Edge density (m/ha) \\
\hline All patches & 30 & $225.4(67.2)[1.1]$ & $0.30(0.03)$ & $208.9(10.4)$ \\
Glaucomys sabrinus & 11 & $403.8(122.2)[4.1]$ & $0.31(0.04)$ & $210.5(22.1)$ \\
Glaucomys volans & 5 & $617.4(234.4)[21.9]$ & $0.44(0.08)$ & $144.5(32.8)$ \\
Sciurus carolinensis & 16 & $231.9(96.3)[1.4]$ & $0.32(0.04)$ & $210.0(15.0)$ \\
Tamiasciurus hudsonicus & 9 & $309.4(136.3)[3.1]$ & $0.32(0.06)$ & $208.5(24.7)$ \\
Tamias striatus & 16 & $203.9(84.7)[2.8]$ & $0.28(0.01)$ & $211.1(13.5)$ \\
\hline
\end{tabular}

Patch area is the area of the sampled forest patch, connectivity is the proportion of forest cover within a 5-km radius of the patch center, and edge density is the density of forest matrix edge within a $5-\mathrm{km}$ radius. Minimum patch area is shown in square brackets 
chipmunks occupied the smallest, least connected patches surrounded by landscapes with the highest amount of edge (Table 1). Only three of 30 patches sampled had both flying squirrel species, and two of these were large patches $(>1,000$ ha).

\section{Species detectability}

Cursorial sciurids were detected well by our level of trapping effort according to latency-to-detection calculations. The mean $[\mathrm{SE}]$ latency to initial detection was 54.5 [13.4] th for gray squirrels, 54.6 [9.2] th for red squirrels, 56.2 [7.4] tn for eastern chipmunks, 50.5 [6.9]tn for northern flying squirrels, and $67.1[31.5]$ th for southern flying squirrels with an overall mean of 88.7 tn undertaken per landscape. Detection probability was highest for southern flying squirrels (0.59) and eastern chipmunks $(0.59)$ and lowest for red squirrels $(0.34$; Table 2$)$.

\section{Body size}

There was no relationship between mean body-size ranks of squirrels and patch area $\left(r_{\mathrm{s}}=0.06, n=26, P>0.05\right)$ or connectivity $\left(r_{\mathrm{s}}=0.02, n=26, P>0.05\right)$. The sample size was 26 for these analyses because squirrels were not detected at four sites (Fig. 1).

\section{Models of patch occupancy}

The top models for predicting occupancy of northern flying squirrels, with $\triangle$ QAICc values $<2$ included patch area, patch area + connectivity, and patch area + edge (Table 3 ). We averaged the confidence set of candidate models and found that patch area had a positive effect and connectivity a negative effect on probability of northern flying squirrel occupancy (Table 4). The effect of edge was negligible. Patch area had a relative importance weight of 0.69 followed by connectivity and edge of 0.26 and 0.13 , respectively (Table 4).

Top models for predicting occupancy of southern flying squirrels with $\triangle$ QAICc values $<2$ contained patch area, the intercept, connectivity + patch area, edge + patch area and connectivity in descending rank order (Table 3). The

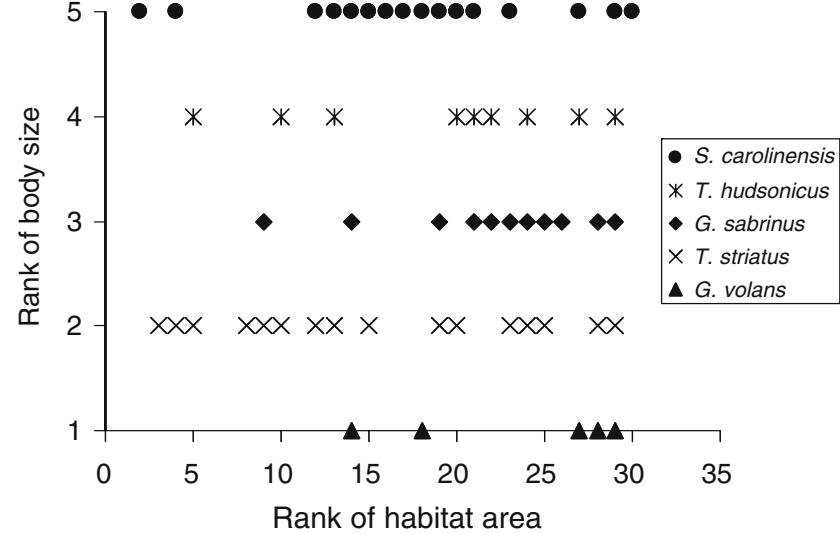

Fig. 1 Matrix of body-size ranks $(1=$ small $)$ and habitat patch area ranks $(1=$ small $)$ for five squirrel species occupying habitat patches of different sizes in a study of patch occupancy by squirrels in central Ontario, Canada during 2004 to 2006. Species in order of decreasing body size were Sciurus carolinensis, Tamiasciurus hudsonicus, Glaucomys sabrinus, Tamias striatus, and Glaucomys volans

model-averaged candidate set included patch area $\left(w_{i}=\right.$ $0.49)$ and connectivity $\left(w_{i}=0.22\right)$, both with positive effects on occupancy (Table 4$)$. Edge $\left(w_{i}=0.11\right)$ had a small negative effect (Table 4). Confidence intervals around parameter estimates of connectivity overlapped zero for the southern flying squirrel occupancy model (Table 4).

Models representing patch area, connectivity, and edge were ranked below the intercept for the three cursorial species (Table 3). However, models with edge, area, and edge + area had $\triangle$ QAICc $<2$ for gray squirrels and similarly the connectivity model had $\triangle$ QAICc $<2$ for eastern chipmunks. Patch area and edge had very small positive effects on gray squirrel occurrence whereas connectivity had a negative effect on chipmunk occurrence (Table 4).

\section{Model performance}

The composite model for predicting occurrence of northern flying squirrels had an AUC value of 0.90 (0.79-1.00). The composite model for southern flying occurrence had an AUC value of 0.63 (0.43-0.84). These AUC values indicate a model with good predictive power for northern flying squirrels and moderate power for southern flying squirrels.
Table 2 The overall probability of detection for 5 squirrel species based on one night of livetrapping in 30 forested landscapes in central Ontario, Canada and the proportion of landscapes occupied with standard error (SE)

\begin{tabular}{lcc}
\hline Species & Detection probability (SE) & Proportion of sites occupied (SE) \\
\hline Glaucomys sabrinus & $0.47(0.09)$ & $0.47(0.11)$ \\
Glaucomys volans & $0.59(0.12)$ & $0.18(0.07)$ \\
Sciurus carolinensis & $0.39(0.08)$ & $0.68(0.14)$ \\
Tamiasciurus hudsonicus & $0.34(0.11)$ & $0.40(0.14)$ \\
Tamias striatus & $0.59(0.08)$ & $0.56(0.10)$ \\
\hline
\end{tabular}


Table 3 Ranking of occupancy models for 30 forest patches in central Ontario, Canada for northern (Glaucomys sabrinus) and southern ( $G$. volans) flying squirrel, eastern gray squirrel (Sciurus carolinensis), American red squirrel (Tamiasciurus hudsonicus), and eastern chipmunk (Tamias striatus) with a number of parameters $(K),-2$ $\log$ likelihood (-2LL), quasilikelihood Akaike's Information Criteria corrected for small sample sizes (QAICc), and difference between top model and model $i(\triangle \mathrm{QAICc})$
Only models with $\Delta$ QAICc $<4$ are presented. Patch area is the area of the sampled forest patch, connectivity is the proportion of forest cover within a $5-\mathrm{km}$ radius of the patch center (controlling for patch area), and edge density is the density of forest-matrix edge within a $5-\mathrm{km}$ radius (controlling for patch area)

\begin{tabular}{|c|c|c|c|c|}
\hline Model & $K$ & $-2 \mathrm{LL}$ & QAICc & $\triangle \mathrm{QAICc}$ \\
\hline \multicolumn{5}{|l|}{ Glaucomys sabrinus } \\
\hline Patch area & 2 & 87.434 & 46.133 & 0.000 \\
\hline Patch area + connectivity & 3 & 83.092 & 46.542 & 0.409 \\
\hline Patch area + edge & 3 & 86.084 & 47.968 & 1.835 \\
\hline Intercept & 1 & 96.980 & 48.383 & 2.250 \\
\hline Patch area + connectivity + edge & 4 & 81.898 & 48.649 & 2.516 \\
\hline Connectivity & 2 & 94.390 & 49.450 & 3.317 \\
\hline \multicolumn{5}{|l|}{ Glaucomys volans } \\
\hline Patch area & 2 & 49.535 & 33.132 & 0.000 \\
\hline Intercept & 1 & 54.925 & 33.952 & 0.820 \\
\hline Connectivity + patch area & 3 & 48.017 & 34.731 & 1.599 \\
\hline Edge + patch area & 3 & 48.352 & 34.926 & 1.794 \\
\hline Connectivity & 2 & 52.731 & 34.983 & 1.851 \\
\hline Edge & 2 & 52.991 & 35.133 & 2.001 \\
\hline Connectivity + edge & 3 & 49.628 & 35.664 & 2.532 \\
\hline Edge + patch area + connectivity & 4 & 45.861 & 36.160 & 3.028 \\
\hline \multicolumn{5}{|l|}{ Sciurus carolinensis } \\
\hline Intercept & 1 & 115.151 & 115.537 & 0.000 \\
\hline Edge & 2 & 113.197 & 115.914 & 0.377 \\
\hline Patch area & 2 & 113.725 & 116.433 & 0.897 \\
\hline Edge + patch area & 3 & 111.578 & 116.798 & 1.262 \\
\hline Connectivity & 2 & 114.940 & 117.630 & 2.094 \\
\hline Edge + connectivity & 3 & 113.026 & 118.224 & 2.687 \\
\hline Connectivity + patch area & 3 & 113.551 & 118.741 & 3.205 \\
\hline Connectivity + edge + patch area & 4 & 111.416 & 119.315 & 3.778 \\
\hline \multicolumn{5}{|l|}{ Tamiasciurus hudsonicus } \\
\hline Intercept & 1 & 77.591 & 51.212 & 0.000 \\
\hline Patch area & 2 & 75.831 & 54.495 & 3.283 \\
\hline \multicolumn{5}{|l|}{ Tamias striatus } \\
\hline Intercept & 1 & 111.483 & 40.819 & 0.000 \\
\hline Connectivity & 2 & 110.542 & 42.794 & 1.975 \\
\hline Edge & 2 & 110.877 & 42.910 & 2.091 \\
\hline Patch area & 2 & 111.460 & 43.112 & 2.294 \\
\hline
\end{tabular}

The AUC values for eastern gray squirrels and eastern chipmunks were $0.70(0.52-0.88)$ and $0.59(0.36-0.83)$, respectively, indicating moderate model performance. The performance of the red squirrel model was not assessed since the intercept ranked above all other models in its ability to predict occurrence.

\section{Patterns of occurrence}

Contour plots illustrated that northern flying squirrels were most likely to occur in large patches embedded in landscapes with low forest habitat connectivity, and they were least likely to occur in small patches in highly connected landscapes. The smallest patch containing a northern flying squirrel was 4.1 ha, but the next smallest was 21.9 ha
(Table 1). Southern flying squirrels were most likely to occur in large, well-connected patches and least likely to occur in small unconnected patches (Fig. 2). Edge density had a negligible effect on probability of occurrence of both flying squirrel species and was omitted from the contour plot for clarity. Caution should be taken in interpretation of these contours plots since confidence intervals are not incorporated into the plots.

\section{Discussion}

Our results supported the prediction that flying squirrels would be more sensitive to habitat patch area than would other squirrel species. We found that patch occupancy of 
Table 4 Weighted parameter estimates of composite logistic models of patch occupancy for 4 squirrel species based on live-trapping in 30 forested landscapes in central Ontario, Canada

\begin{tabular}{|c|c|c|c|c|c|}
\hline \multirow[b]{2}{*}{ Parameter } & \multirow[b]{2}{*}{ Estimate } & \multirow[b]{2}{*}{ SE } & \multicolumn{2}{|c|}{$95 \%$ CI } & \multirow{2}{*}{$\begin{array}{l}\text { Importance } \\
w_{i}\end{array}$} \\
\hline & & & Upper & Lower & \\
\hline \multicolumn{6}{|c|}{ Glaucomys sabrinus } \\
\hline Patch area & 1.93 & 0.83 & 3.35 & 0.51 & 0.69 \\
\hline Connectivity & -11.05 & 4.62 & -3.19 & -18.92 & 0.26 \\
\hline Edge & 0.02 & 0.01 & 0.04 & 0.00 & 0.13 \\
\hline Intercept & -3.36 & 1.35 & -1.07 & -5.66 & \\
\hline \multicolumn{6}{|c|}{ Glaucomys volans } \\
\hline Patch area & 1.37 & 0.55 & 2.32 & 0.43 & 0.49 \\
\hline Connectivity & 5.96 & 4.61 & 13.81 & -1.90 & 0.22 \\
\hline Edge & -0.02 & 0.02 & 0.01 & -0.04 & 0.11 \\
\hline Intercept & -3.19 & 0.96 & -1.57 & -4.82 & \\
\hline \multicolumn{6}{|c|}{ Sciurus carolinensis } \\
\hline Patch area & 0.63 & 0.21 & 0.98 & 0.27 & 0.30 \\
\hline Edge & 0.02 & 0.0004 & 0.02 & 0.02 & 0.13 \\
\hline Intercept & 0.06 & 0.93 & 1.64 & -1.52 & \\
\hline \multicolumn{6}{|l|}{ Tamias striatus } \\
\hline Connectivity & -3.44 & 3.59 & 2.68 & -9.56 & 0.16 \\
\hline Intercept & 0.38 & 0.29 & 0.88 & -0.11 & \\
\hline
\end{tabular}

Patch area is the area of the sampled forest patch, connectivity is the proportion of forest cover within a $5-\mathrm{km}$ radius of the patch center (controlling for patch area), and edge density is the density of forestmatrix edge within a $5-\mathrm{km}$ radius (controlling for patch area)

both northern and southern flying squirrels was positively related to habitat patch area. In contrast to the results for flying squirrels, there was little evidence of an area effect (either positive or negative) for the cursorial squirrel species. Of this group, only gray squirrels had a weak, positive effect of patch area. Our findings are consistent with the hypothesis that squirrel species that socially thermoregulate in winter are sensitive to patch area, possibly owing to an Allee effect. Thus, squirrels appear to provide an example where behavioral traits can lead to inconsistent responses to landscape fragmentation among species.

Because of their close conceptual relationship with habitat area, Allee effects are considered to be highly relevant for landscape ecology and the conservation of fragmented populations (Stephens and Sutherland 1999; Morris 2002), although they have not been studied much in this context. Recently, however, Gardner (2004) suggested that winter flocking in speckled warblers (Chthonicola sagittata) resulted in populations being extirpated from woodlots smaller than 40 ha. Similarly, a few studies have found apparent habitat area thresholds in flying squirrels. For example, Nupp and Swihart (2000) found in Indiana that no forest patches $<6$ ha were occupied. They concluded that the huddling life history strategy "may make southern flying squirrels particularly vulnerable to extinction in small woodlots with few individuals, especially at northern latitudes" (Nupp and Swihart 2000: 523). Rosenblatt et al. (1999) found in their Illinois study that no patches $<65$ ha were occupied by $G$. volans. Patterson and Malcolm (2010) estimated a habitat area threshold of 48 ha for $G$. sabrinus. The Siberian flying squirrel (Pteromys volans) also appears to be absent from small habitat patches (Hurme et al. 2007). Given that winter nest group sizes may vary with latitude in flying squirrels (Muul 1974), we expect that the severity of an

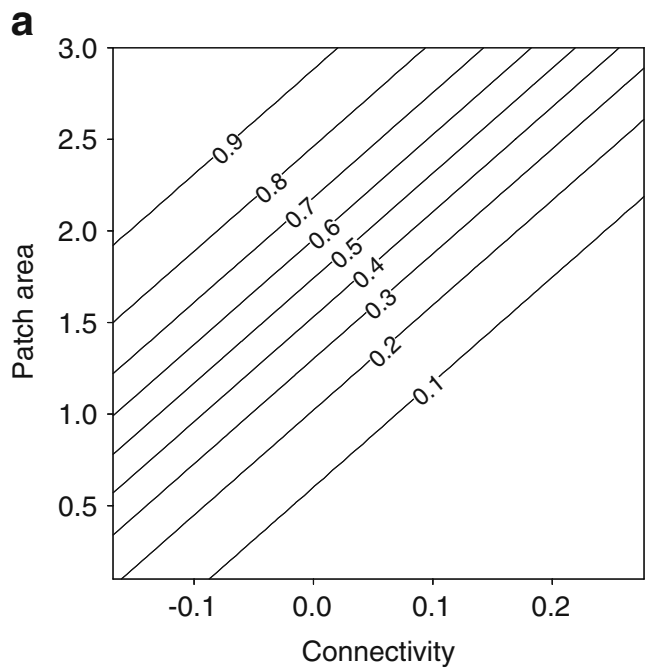

b

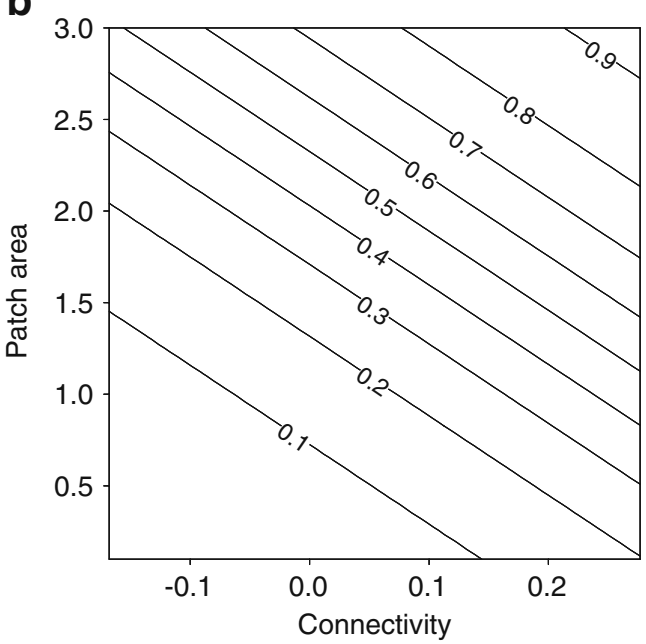

Fig. 2 Contour plot illustrating patterns of northern flying squirrel (Glaucomys sabrinus; a) and southern flying squirrel $(G$. volans; b) occupancy in central Ontario, Canada in relation to $\log _{10}$-transformed habitat patch area (ha) and structural landscape connectivity within $5,000-\mathrm{m}$ of patch centroid. Connectivity is measured as the residuals of the regression between $\log _{10}$-transformed habitat patch area and the proportion of the landscape around the patch that was forested (within a 5,000-m radius) 
Allee effect, and therefore the average size of minimum habitat patches would vary with latitude (i.e., is greater farther north). However, more empirical estimates of flying squirrel nesting group size and area effects at varying latitudes are required to test this idea.

We also predicted that flying squirrels would be more sensitive than cursorial squirrels to structural forest connectivity; however, this prediction was not fully supported. Consistent with our prediction, we did not find evidence that patch occupancy by cursorial squirrels was affected by connectivity-suggesting that colonization of patches by these species is not limited by patch isolation, at least within the spatial scale we assessed. Flying squirrels had a complex relationship with landscape connectivity. Our surveys revealed that northern flying squirrels were most likely to occur in large patches embedded in landscapes with low connectivity, and they were least likely to occur in small patches in highly connected landscapes. Conversely, southern flying squirrels were most likely to occur in large, wellconnected patches and least likely to occur in small, unconnected patches. It has been previously suggested that the flying squirrel species have a reciprocal distribution at a larger spatial scale in Ontario (Bowman et al. 2005). Others (Price et al. 1988; Wetzel and Weigl 1994) have hypothesized that these two species may exhibit parasite-mediated competition. The suggested parasite is Strongyloides robustus which the southern flying squirrel can apparently tolerate better than the northern species. When the squirrel species are sympatric, this parasite may be spread from the southern flying squirrel to the northern flying squirrel to the latter species' detriment (Wetzel and Weigl 1994). The relationships between flying squirrel patch occupancy and our measures of connectivity are what we would expect if northern flying squirrels were competitively excluded from large patches in high connectivity landscapes by their southern congeners. This pattern also suggests, however, that patch occupancy by northern flying squirrels is not limited by structural landscape connectivity.

Alternative explanations for the patch area effect that we observed in flying squirrels include loss of genetic diversity or mating opportunities in small patches due to disrupted dispersal (Lande et al. 2003). Our connectivity results, however, combined with a growing list of recent findings about flying squirrel movement (Bowman et al. 2005; Rizkalla and Swihart 2007), distributions (Patterson and Malcolm 2010), and lack of genetic structure (McEachen 2007), suggest that difficulty dispersing may not be an important factor affecting patch occupancy by flying squirrels.

We found no support in this study for hypotheses relating patch occupancy to body size. In fact, the smallest bodied species $(G$. volans) was absent from the smallest patches, which is opposite to the pattern expected from allometrically scaled population densities (Nupp and Swihart 2000).

The northern flying squirrel and the red squirrel typically inhabit coniferous forests (Goheen and Swihart 2005; Holloway and Malcolm 2006). In this study, our sampling was limited to mature deciduous forest types. Although the red squirrel did not respond to patch area, we do not believe this result was confounded by sampling deciduous rather than coniferous forests. If, like the northern flying squirrel, the red squirrel was sensitive to area, we would expect to detect this pattern in patch occupancy. Instead, it appears that the red squirrel is plastic enough to be an opportunist in a fragmented, largely deciduous forest landscape. Bayne and Hobson (1998) came to a similar conclusion in a study of the red squirrel in western Canada.

Finally, we did not include a measure of matrix quality in our analysis. The matrix land use represented a hard edge along forest patch edges. Despite the presence of different agricultural crops surrounding different patches, we feel that the functional qualities of the crop types were similar relative to the importance of forest cover in the landscape. Moreover, as our hypotheses pertained to trees in the landscape (rather than matrix composition), we opted to simplify our models by excluding a matrix term.

In summary, it appeared from our research that both flying squirrel species, and to a lesser extent, gray squirrels, were sensitive to habitat patch area, in a fashion consistent with the presence of an Allee effect in winter. This suggests that a behavioral trait-group nesting - may have a synergy with landscape fragmentation that produces a predictable pattern of patch occupancy. We recommend that further research into Allee effects in flying squirrels should directly test for effects of group size on winter survival. Our results concerning landscape connectivity were more equivocal, suggesting that at least one volant species, the northern flying squirrel, was able to occupy structurally unconnected habitats. Cursorial squirrels however, showed no strong effects of either patch area or landscape connectivity on patterns of occupancy. Overall, we conclude that in this system, species-specific behavioral traits lead to inconsistent responses to landscape fragmentation and thus, are important to understand.

Acknowledgments This study received financial support from a Natural Sciences and Engineering Research Council of Canada Discovery Grant to JB, from the Ontario Ministry of Natural Resources (OMNR) Wildlife Research and Development Section, and from the OMNR Climate Change Fund. We would like to thank E. Nol and C.J. Garroway for reviewing the manuscript as well as the numerous people who contributed in the field, including B. Walpole, A. Tamlin, C.J. Garroway, J. Castle, K. Walpole, and R. Varrin. Thanks to K. Middel for help with GIS and L. Nguyen and C.J. Garroway for their guidance with statistics. Finally, thanks to the many private woodlot owners who participated in this study. 


\section{References}

Anderson DR (2008) Model based inference in the life sciences: a primer on evidence. Springer, New York, pp 1-184. doi:10.1007/ 978-0-387-74075-1

Bayne EM, Hobson KA (1998) The effects of habitat fragmentation by forestry and agriculture on the abundance of small mammals in the southern boreal mixedwood forest. Can J Zool 76:62-69. doi:10.1139/cjz-76-1-62

Bender DJ, Tischendorf L, Fahrig L (2003) Using patch isolation metrics to predict animal movement in binary landscapes. Landsc Ecol 18:17-39. doi:10.1023/A:1022937226820

Bowman J, Fahrig L (2002) Gap crossing by chipmunks: an experimental test of landscape connectivity. Can J Zool 80:1556-1561. doi:10.1139/z02-161

Bowman J, Cappuccino N, Fahrig L (2002a) Patch size and population density: the effect of immigration behavior. Conserv Ecol 6(1): 9 [online] URL: http://www.consecol.org/vol6/iss1/art9

Bowman J, Jaeger JAG, Fahrig L (2002b) Dispersal distance of mammals is proportional to home range size. Ecol 87:2049-2055. doi:10.1890/0012-9658(2002)083[2049:DDOMIP]2.0.CO;2

Bowman J, Holloway GL, Malcolm JR, Middel KR, Wilson PJ (2005) Northern range boundary dynamics of southern flying squirrels: evidence of an energetic bottleneck. Can J Zool 8:1486-1494. doi:10.1139/z05-144

Boyce MS, Vernier PR, Nielsen SE, Schmiegelow FKA (2002) Evaluating resource selection functions. Ecol Model 157:281300. doi:10.1016/S0304-3800(02)00200-4

Bright PW (1993) Habitat fragmentation-problems and predictions for British mammals. Mamm Rev 23:101-111. doi:10.1111/j.13652907.1993.tb00420.x

Brown JH, Kodric-Brown A (1977) Turnover rates in insular biogeography: effect of immigration on extinction. Ecol 58:445-449. doi:10.2307/1935620

Burnham KP, Anderson DR (2002) Model selection and multimodel inference: a practical information - theoretic approach, 2nd edn. Springer, New York, pp 1-496

Caughley G, Gunn A (1996) Conservation biology in theory and practice. Blackwell Science, Oxford, England, pp 1-459

Chambers BA, Naylor BJ, Nieppola J, Merchant B, Uhlig P (1997) Field guide to forest ecosystems of central Ontario. Ontario Ministry of Natural Resources, Queen's Printer, Ontario, pp 1-200

Cotton CL, Parker KL (2000) Winter activity patterns of northern flying squirrels in sub-boreal forests. Can J Zool 7:1895-1901. doi:10.1139/cjz-78-11-1896

Courchamp F, Clutton-Brock T, Grenfell B (1999) Inverse density dependence and the Allee effect. Trends Ecol Evol 14:405-410. doi:10.1016/S0169-5347(99)01683-3

Elkie P, Rempel R, Carr A (1999) Patch analyst user's manual. Ontario Ministry of Natural Resources, Queen's Printer, Ontario, pp 1-22

Fahrig L (2001) How much habitat is enough? Biol Conserv 100:6574. doi:10.1016/S0006-3207(00)00208-1

Fahrig L (2002) Effect of habitat fragmentation on the extinction threshold: a synthesis. Ecol Appl 12:346-353. doi:10.2307/ 3060946

Fahrig L (2003) Effect of habitat fragmentation on biodiversity. Annu Rev Ecol Evol Syst 34:487-515. doi:10.1146/annurev. ecolsys.34.011802.132419

Ferraz G, Nichols JD, Hines JE, Stouffer PC, Bierregaard RO, Lovejoy TE (2007) A large-scale deforestation experiment: effects of patch area and isolation on Amazon birds. Sci 315:238-241. doi:10.1126/science.1133097

Fischer J, Lindenmayer DB (2007) Landscape modification and habitat fragmentation: a synthesis. Glob Ecol Biogeogr 16:265280. doi:10.1111/j.1466-8238.2007.00287.x
Gardner JL (2004) Winter flocking behaviour of speckled warblers and the Allee effect. Biol Conserv 118:195-204. doi:10.1016/j. biocon.2003.08.018

Garroway CJ, Bowman J, Cascaden TJ, Holloway GL, Mahan CG, Malcolm JR, Steele MA, Turner G, Wilson PJ (2010) Climate change induced hybridization in flying squirrels. Glob Chang Biol 16:113-121. doi:10.1111/j.1365-2486.2009.01948.x

Goheen JR, Swihart RK (2005) Resource selection and predation of North American red squirrels in deciduous forest fragments. J Mamm 86:22-28. doi:10.1644/1545-1542(2005)086<0022:RSAPON $>2.0$. $\mathrm{CO} ; 2$

Hale ML, Lurz PWW, Shirley MDF, Rushton S, Fuller RM, Wolff K (2001) Impact of landscape management on the genetic structure of red squirrel populations. Sci 21:2246-2248. doi:10.1126/ science. 1062574

Hines JE (2006) PRESENCE2- Software to estimate patch occupancy and related parameters. USGS-PWRC. http://www.mbr-pwrc.usgs. gov/software/presence.html

Holloway GL, Malcolm JR (2006) Sciurid habitat relationships in forests managed under selection and shelterwood silviculture in Ontario. J Wildl Manage 70:1735-1745. doi:10.2193/0022-541X(2006)70 [1735:SHRIFM]2.0.CO;2

Hosmer DW, Lemeshow S (2000) Applied logistic regression, 2nd edn. Wiley, Toronto, pp 1-392. doi:10.1002/0471722146

Hurme E, Reunanen P, Mönkönen M, Nikula A, Nivala V, Oksanen J (2007) Local habitat patch pattern of the Siberian flying squirrel in a managed boreal forest landscape. Ecography 30:277-287. doi:10.1111/j.2007.0906-7590.04744.x

Jaeger JAG, Bowman J, Brennan J, Fahrig L, Bert D, Bouchard J, Charbonneau N, Frank K, Gruber B, Tluk von Toschanowitz K (2005) Predicting when animal populations are at risk from roads: an interactive model of road avoidance behavior. Ecol Model 185:329348. doi:10.1016/j.ecolmodel.2004.12.015

Koper N, Schmiegelow FKA, Merrill EH (2007) Residuals cannot distinguish between ecological effects of habitat amount and fragmentation: implications for the debate. Landsc Ecol 22:811820. doi:10.1007/s10980-007-9083-9

Koprowksi JL (1996) Natal philopatry, communal nesting, and kinship in fox squirrels and gray squirrels. J Mamm 77:10061016. doi: $10.2307 / 1382781$

Koprowski JL (2005) The response of tree squirrels to fragmentation: a review and synthesis. Anim Conserv 8:369-376. doi:10.1017/ S1367943005002416

Lande R, Engen S, Saether B-E (2003) Stochastic population dynamics in ecology and conservation. Oxford University Press, Oxford, pp 1224. doi:10.1093/acprof:oso/9780198525257.001.0001

Laurance WF (1991) Ecological correlates of extinction proneness in Australian tropical rainforest mammals. Conserv Biol 5:79-89. doi:10.1111/j.1523-1739.1991.tb00390.x

Lima SL, Zollner PA (1996) Towards a behavioral ecology of ecological landscapes. Trends Ecol Evol 11:131-135. doi:10.1016/0169-5347 (96)81094-9

MacKenzie DI, Nichols JD, Lachman GB, Droege S, Royle JA, Langtimm CA (2002) Estimating site occupancy rates when detection probabilities are less than one. Ecol 83:2248-2255. doi:10.1890/0012-9658(2002)083[2248:ESORWD]2.0.CO;2

MacKenzie DI, Nichols JD, Hines JE, Knutson MG, Franklin AB (2003) Estimating site occupancy, colonization and local extinction probabilities when a species is detected imperfectly. Ecol 84:2200-2207. doi:10.1890/02-3090

Manel S, Williams HC, Ormerod SJ (2001) Evaluating presenceabsence models in ecology: the need to account for prevalence. $\mathrm{J}$ Appl Ecol 38:921-931. doi:10.1046/j.1365-2664.2001.00647.x

McEachen TJ (2007) A genetic test of range expansion by the southern flying squirrel (Glaucomys volans) at its northern range boundary. M.Sc. Thesis, Trent University, Peterborough, pp 1-46 
Mech SG, Zollner PA (2002) Using body size to predict perceptual range. Oikos 98:47-52. doi:10.1034/j.1600-0706.2002.980105.x

Merritt JF, Zegers DA, Rose LR (2001) Seasonal thermogenesis of southern flying squirrels (Glaucomys volans). J Mamm 82:5164. doi:10.1644/1545-1542(2001)082<0051:STOSFS $>2.0 . C O ; 2$

Moilanen A, Hanski I (1998) Metapopulation dynamics: effects of habitat quality and landscape structure. Ecol 79:2503-2515. doi:10.1890/0012-9658(1998)079[2503:MDEOHQ]2.0.CO;2

Moilanen A, Nieminen M (2002) Simple connectivity measures in spatial ecology. Ecol 83:1131-1145. doi:10.1890/0012-9658 (2002)083[1131:SCMISE]2.0.CO;2

Moore JE, Swihart RK (2005) Modeling patch occupancy by forest rodents: incorporating detectability and spatial autocorrelation with hierarchically structured data. J Wildl Manage 69:933-949. doi:10.2193/0022-541X(2005)069[0933:MPOBFR]2.0.CO;2

Morris DW (2002) Measuring the Allee effect: positive density dependence in small mammals. Ecol 83:14-20. doi:10.1890/ 0012-9658(2002)083[0014:MTAEPD]2.0.CO;2

Muul I (1974) Geographic variation in the nesting habits of Glaucomys volans. J Mamm 55:840-844. doi:10.2307/1379415

Nupp TE, Swihart RK (2000) Landscape-level correlates of small mammal assemblages in forest fragments of farmland. J Mamm 81:512-526. doi:10.1644/1545-1542(2000)081<0512:LLCOSM>2.0.CO;2

Ostfeld RS, LoGiudice K (2003) Community disassembly, biodiversity loss, and the erosion of an ecosystem service. Ecol 84:14211427. doi: $10.1890 / 02-3125$

Patterson JEH, Malcolm JR (2010) Landscape structure and local habitat characteristics as correlates of Glaucomys sabrinus and Tamiasciurus hudsonicus occurrence. J Mamm 91:642-653. doi:10.1644/09-MAMM-A-118.1

Price PW, Westoby M, Rice B (1988) Parasite-mediated competition: some predictions and tests. Am Midl Nat 131:544-555. doi:10.1086/284805

Prugh LR, Hodges KE, Sinclair ARE, Brashares JS (2008) Effect of habitat area and isolation on fragmented animal populations. Proc Natl Acad Sci 105:20770-20775. doi:10.1073/pnas.0806080105

Reunanen P, Grubb TC Jr (2005) Densities of eastern chipmunks (Tamias striatus) in farmland woodlots decline with increasing area and isolation. Am Midl Nat 154:433-441. doi:10.1674/ 0003-0031(2005)154[0433:DOECTS]2.0.CO;2

Ritchie LE, Betts MG, Forbes G, Vernes K (2009) Effects of landscape composition and configuration on northern flying squirrels in a forest mosaic. For Ecol Manag 257:1920-1929. doi:10.1016/j.foreco.2009.01.028

Rizkalla CE, Swihart RK (2007) Explaining movement decisions by forest rodents in fragmented landscapes. Biol Conserv 140:339348. doi:10.1016/j.biocon.2007.08.019

Rosenblatt DL, Heske EJ, Nelson SL, Barber DM, Miller MA, MacAllister B (1999) Forest fragments in East-central Illinois: islands or habitat patches for mammals? Am Midl Nat 141:115123. doi:10.1674/0003-0031(1999)141[0115:FFIECI]2.0.CO;2

Selonen V, Hanski IK (2003) Movements of the flying squirrel Pteromys volans in corridors and in matrix habitat. Ecography 26:641-651. doi:10.1034/j.1600-0587.2003.03548.x

Shaffer ML (1981) Minimum population sizes for species conservation. Biosci 31:131-134. doi:10.2307/1308256

Stapp P, Pekins P, Mautz WW (1991) Winter energy expenditure and the distribution of southern flying squirrels. Can J Zool 69:2548 2555. doi: $10.1139 /$ / $91-359$

Stephens PA, Sutherland WJ (1999) Consequences of the Allee effect for behavior, ecology and conservation. Trends Ecol Evol 14:401-405. doi:10.1016/S0169-5347(99)01684-5

Taulman JF, Smith KG (2004) Home range and habitat selection of southern flying squirrels in fragmented forests. Mamm Biol 69:11-27. doi:10.1078/1616-5047-113

Vernes K (2001) Gliding performance of the northern flying squirrel (Glaucomys sabrinus) in mature mixed forest of eastern Canada. J Mamm 82:1026-1033. doi:10.1644/1545-1542(2001) 082<1026:GPOTNF $>2.0 . \mathrm{CO} ; 2$

Wetzel EJ, Weigl PD (1994) Ecological implications for flying squirrels (Glaucomys spp.) of effects of temperature on the invitro development and behavior of Strongyloides robustus. Am Midl Nat 128:156-167. doi:10.2307/2426607

Wilder SM, Meikle DB (2006) Variation in effects of fragmentation on the white-footed mouse (Peromyscus leucopus) during the breeding season. J Mamm 87:117-123. doi:10.1644/05-MAMM-A-035R1.1 